\title{
Electrical and optical properties of Be doped InP grown at low temperature by solid source atomic layer molecular beam epitaxy
}

\author{
P. A. Postigo, ${ }^{\text {a) }}$ M. L. Dotor, P. Huertas, F. García, D. Golmayo, and F. Briones \\ Instituto de Microelectrónica de Madrid (IMM-CNM-CSIC) Isaac Newton, 8-Parque Tecnológico de Madrid- \\ 28760 Tres Canto, Madrid, Spain
}

(Received 10 August 1998; accepted for publication 4 February 1999)

\begin{abstract}
Beryllium-doped InP layers have been grown by solid source atomic layer molecular beam epitaxy at low substrate temperature. The residual $n$-type doping was reduced by controlling both the amplitude and the length of the phosphorus pulse. We have shown a well controlled $p$-type doping and obtained a hole concentration in the range $4 \times 10^{17}-3 \times 10^{19} \mathrm{~cm}^{-3}$ at room temperature. The electrical and optical properties of InP layers grown at low temperatures were investigated by Hall effect and photoluminescence (PL) measurements. PL spectra for lightly doped samples have a near band emission at $1.41 \mathrm{eV}$ and Be-related emissions around $1.38 \mathrm{eV}$. (c) 1999 American Institute of Physics. [S0021-8979(99)09809-6]
\end{abstract}

\section{INTRODUCTION}

Atomic layer molecular beam epitaxy (ALMBE) ${ }^{1}$ using valved solid source cracking cells has been shown to be especially adequate for growing phosphorus based III-V compounds $^{2}$ at low substrate temperature (LT) with abrupt interfaces and doping profiles with low doping diffusion. Also, it has been shown to be very useful in the growth of pseudoquaternary alloys $\operatorname{In}_{1-x} \mathrm{Ga}_{x} \mathrm{As}_{y} \mathrm{P}_{1-\mathrm{y}}$ in the form of $(\operatorname{InP}) /\left(\mathrm{In}_{0.53} \mathrm{Ga}_{0.47} \mathrm{As}\right)$ short period superlattices ${ }^{3}$ and it is very suitable for the monolithic integration of optoelectronic devices with prefabricated circuits. However, the high level of stoichiometric related defects act as residual donors in LT grown $\operatorname{InP}^{4-7}$ and make it difficult to obtain $p$-type InP layers. Using solid-source phosphorus and a valved-cracker cell, we have shown ${ }^{8-10}$ that by a close control of phosphorus pulses during ALMBE growth of InP at LT $\left(\leqslant 400^{\circ} \mathrm{C}\right)$, it is possible to reduce the residual $n$-type doping down to $n \sim 1$ $\times 10^{16} \mathrm{~cm}^{-3}$, and to reach $p$ doping using Be in the range of $4 \times 10^{17}-3 \times 10^{19} \mathrm{~cm}^{-3}$. In this work we describe the electrical and optical properties of Be-doped InP epilayers grown at low temperature by solid source ALMBE.

\section{EXPERIMENT}

InP epitaxial layers have been grown on Fe-doped (100) InP substrate, in a standard MBE system. As and P effusion cells are designed to operate in pulse mode by incorporating fast acting, valved-cracker cells for ALMBE growth. In this technique, the molecular beam of the group $\mathrm{V}$ is modulated by opening the valve of the group $\mathrm{V}$ cell only a fraction $t$ of the time $T$ needed for the deposition of 1 monolayer (ML) of InP, that is set by the temperature of the group III cell. The amplitude of the group V pulse can be controlled to supply the right amount of phosphorus during the time $t$. For all layers presented in this work, the growth rate $r_{g}\left(r_{g}=1 / T\right)$

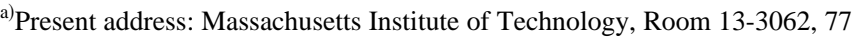
Mass. Ave., Cambridge, MA 02139; electronic mail: aitor @oevlsi.mit.edu
}

was 1 monolayer per second (ML/s), the phosphorus pulse length was $t=0.6 \mathrm{~s}$, and the phosphorus pulse amplitude [beam equivalent pressure (BEP)] was $1.0 \times 10^{-6} \mathrm{mb}$. We have used reflection high-energy electron diffraction (RHEED) to monitor the surface reconstruction during growth, and reflectance difference (RD) to control in situ the surface stoichiometry. ${ }^{9}$ The RHEED diffraction pattern when growing by ALMBE under optimized growth conditions $(t$ $=0.6 \mathrm{~s}$ and $\mathrm{BEP}=1.0 \times 10^{-6} \mathrm{mb}$ ) that minimize residual $n$-type doping, alternates from a P-stabilized $(2 \times 1)$ during the $\mathrm{P}_{2}$ pulse, to In-stabilized $(2 \times 4)$ shortly after the $\mathrm{P}_{2}$ beam is shut off. ${ }^{89}$ Growth of intentionally undoped LT InP layers using the above conditions has shown $n$-type with carrier concentration of $n \sim 1 \times 10^{16} \mathrm{~cm}^{-3}$ and electron mobilities of $\mu \sim 3200 \mathrm{~cm}^{2} / \mathrm{V} \mathrm{s}$ at room temperature. The details of the properties of undoped InP layers have been presented previously. ${ }^{10,11}$ Using optimized growth conditions for ALMBE, we have obtained $p$-type layers doped with $\mathrm{Be}$, with hole concentrations in the range $10^{17}-10^{19} \mathrm{~cm}^{-3}$. The thickness of the layers was $1 \mu \mathrm{m}$ for samples with $p \leqslant 2$ $\times 10^{18} \mathrm{~cm}^{-3}$, grown at a substrate temperature of $400^{\circ} \mathrm{C}$, and $0.2 \mu \mathrm{m}$ for those with $p \geqslant 8 \times 10^{18} \mathrm{~cm}^{-3}$, grown at $360^{\circ} \mathrm{C}$.

\section{ELECTRICAL PROPERTIES}

The electrical properties of Be-doped InP samples have been studied by Hall measurements in the $20-300 \mathrm{~K}$ range. To perform these measurements, four In-Zn alloy dots were placed on the surface of the as-grown layers, followed by a heat treatment for $3 \mathrm{~min}$ at $250{ }^{\circ} \mathrm{C}$ in forming gas, to make ohmic contacts. Hole concentration and mobility data obtained at room temperature are summarized in Table I. These values are comparable to those of bulk InP doped with different elements, ${ }^{12,13}$ and to those of Be-doped InP epilayers grown at $450{ }^{\circ} \mathrm{C}$ by solid source $\mathrm{MBE}^{14}$ and at $525^{\circ} \mathrm{C}$ by gas source MBE. ${ }^{15}$

Figure 1 shows the evolution of the hole concentration as function of $1 / T$. The moderate doped samples ( $p$ ranging from $2.0 \times 10^{17}$ to $1.8 \times 10^{18} \mathrm{~cm}^{-3}$ ) shows at low temperature 
TABLE I. Electrical characteristics at room temperature of the Be-doped InP samples.

\begin{tabular}{cccc}
\hline \hline $\begin{array}{c}\text { Sample } \\
\text { No. }\end{array}$ & $\begin{array}{c}\text { Hole } \\
\text { concentration } \\
\left(\mathrm{cm}^{-3}\right)\end{array}$ & $\begin{array}{c}\text { Mobility } \\
\left(\mathrm{cm}^{2} / \mathrm{V} \mathrm{s}\right)\end{array}$ & $\begin{array}{c}\text { Growth } \\
\text { temperature } \\
\left({ }^{\circ} \mathrm{C}\right)\end{array}$ \\
\hline S1 & $2.0 \times 10^{17}$ & 80 & 400 \\
S2 & $5.5 \times 10^{17}$ & 70 & 400 \\
S3 & $1.0 \times 10^{18}$ & 65 & 400 \\
S4 & $1.8 \times 10^{18}$ & 62 & 400 \\
S5 & $1.0 \times 10^{19}$ & 42 & 360 \\
S6 & $3.0 \times 10^{19}$ & 25 & 360 \\
\hline \hline
\end{tabular}

a clear deviation from the behavior associated to a normal impurity ionization process. The slow increase with temperature in the carrier concentration has a kink after reach $\sim 150$ $\mathrm{K}$, increasing much faster. This change of slope occurs at higher temperatures as the doping level of the sample increases. This behavior has been observed in undoped InP with a concentration of residual donors of $n(300 \mathrm{~K}) \sim 1$ $\times 10^{16} \mathrm{~cm}^{-3}$, grown by $\mathrm{ALMBE}^{10}$ and by liquid phase epitaxy, ${ }^{6}$ and it has been attributed to a two-band conduction process involving the conduction band and an impurity band. In the heavily doped samples, with a hole concentration at room temperature above $p=1 \times 10^{19} \mathrm{~cm}^{-3}$, the temperature dependence of the hole concentration becomes very weak due to the carrier degeneracy. Figure 2 shows dependence of hole mobility with the temperature. The obtained data are comparable to those of bulk InP doped with different elements showing similar room temperature hole concentration. ${ }^{16}$ The dropping of the mobility at lower temperature indicates the onset of impurity band conduction. In agreement with the behavior of the carrier concentration, this mobility drop appears at higher temperature as the doping level increases. The sample S1 which has the lowest doping level shows the highest mobility value obtained for all samples of $\mu=300 \mathrm{~cm}^{2} \mathrm{~V}^{-1} \mathrm{~s}^{-1}$ at $50 \mathrm{~K}$. The sample with

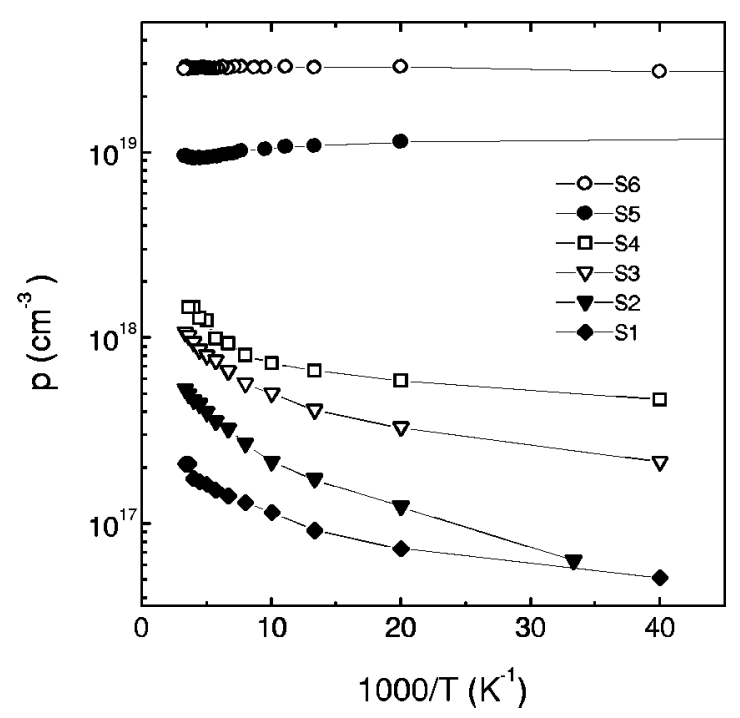

FIG. 1. Temperature dependence of the hole concentration for the samples in Table I.

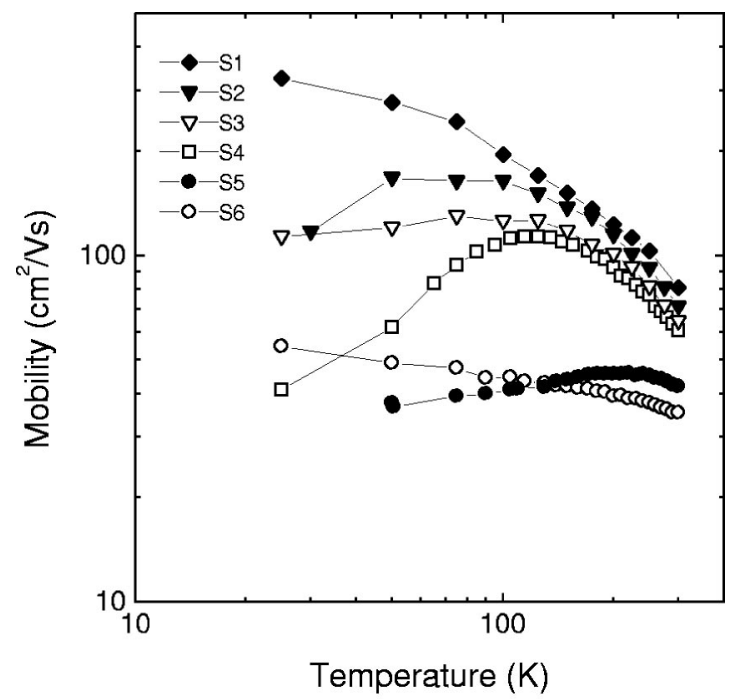

FIG. 2. Hole mobility vs temperature for the samples in Table I.

$p(300 \mathrm{~K})=3 \times 10^{19} \mathrm{~cm}^{-3}$ does not show a drop of mobility at low temperature, according to a behavior of full carrier degeneration.

\section{OPTICAL PROPERTIES}

We measured the photoluminescence (PL) spectrum of the layers to evaluate the optical properties of the samples. The optical setup consisted of an Ar laser, a close cycle helium cryostat, a $\mathrm{Si}$ photodiode, and a $22 \mathrm{~cm}$ monochromator.

Figure 3 shows the evolution of the PL spectrum at $77 \mathrm{~K}$ with the hole concentration, for an incident power density of $\sim 60 \mathrm{~W} / \mathrm{cm}^{2}$. The band-acceptor (BA) transition is observed at $1.38 \mathrm{eV}$ and the band to band transition $(\mathrm{BB})$, at $1.41 \mathrm{eV}$, whereas a transition band appears at $\sim 1.34 \mathrm{eV}$. These spectra are similar to those observed in InP epilayers grown by MBE. ${ }^{14,17}$ and by chemical beam epitaxy, ${ }^{18}$ where transitions at $\sim 1.34 \mathrm{eV}$ are weakly observed at $77 \mathrm{~K}$.

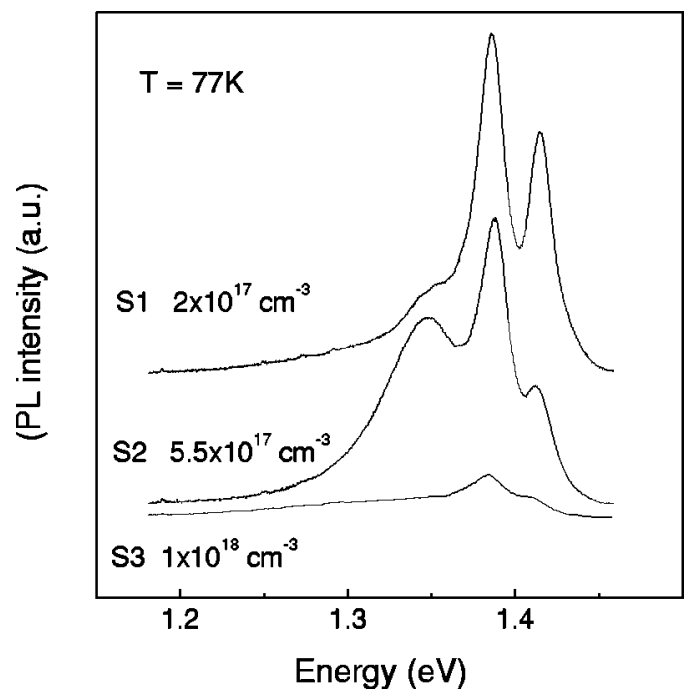

FIG. 3. Hole concentration dependence of PL spectra at $77 \mathrm{~K}$. 


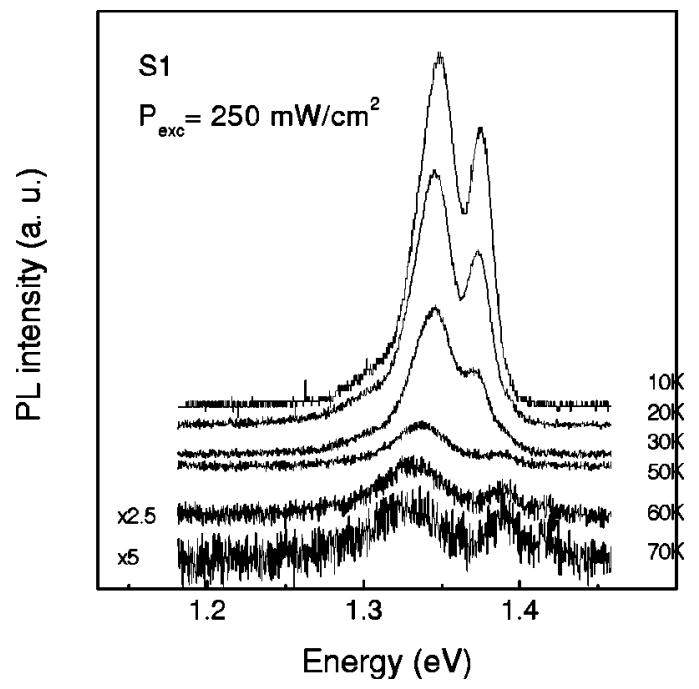

FIG. 4. Dependence of PL spectra with temperature for sample $\mathrm{S} 1\left(p_{300 \mathrm{~K}}\right.$ $\left.=2 \times 10^{17} \mathrm{~cm}^{-3}\right)$.

Figure 4 shows the evolution of the PL spectrum for sample $\mathrm{S} 1\left(p_{300 \mathrm{~K}}=2 \times 10^{17} \mathrm{~cm}^{-3}\right)$ with temperature in the $10-77 \mathrm{~K}$ range, and with an excitation density of $\sim 250$ $\mathrm{mW} / \mathrm{cm}^{2}$. The donor-acceptor pair (DA) transition is observed at $\sim 1.37 \mathrm{eV}$ in the range $10-30 \mathrm{~K}$ and a transition at $\sim 1.35 \mathrm{eV}$ is also clearly distinguished from the DA transition. The BA transition emerges at $20 \mathrm{~K}$, being clearly visible at $50 \mathrm{~K}$, as well as the $\mathrm{BB}$ transition at $\sim 1.41 \mathrm{eV}$. This result is consistent with a switch between the DA and the BA emissions due to the thermal ionization of the donor atoms. The difference of energies between the BA and the DA transitions is about $12 \mathrm{meV}$ higher than the $4 \mathrm{meV}$ reported in $\mathrm{Zn}, \mathrm{Mg}$, and Ca-doped InP. ${ }^{19,20}$ The value of $12 \mathrm{meV}$ that we found is consistent with a donor binding energy deeper than $\sim 7 \mathrm{meV}$, which is the reported value for the common residual donors $(\mathrm{Si}, \mathrm{S})$ of high purity InP. ${ }^{20,21}$ Nevertheless, Hall measurements made in our unintentionally doped InP epilayers, yielded a value for the donor binding energy ${ }^{10}$ of $15 \mathrm{meV}$, which correlates better with the observed energy difference between the BA and DA transitions.

Figure 5 shows the PL spectra at $77 \mathrm{~K}$ obtained from sample S1 for different values of excitation power density $P_{\text {ex }}$. As the excitation power increases, the peaks at 1.38 and $1.41 \mathrm{eV}$ dominate the spectra. The BA transition does not change with the power, but the band at $\sim 1.35 \mathrm{eV}$ shifts to lower energies as the excitation power density decreases, approximately $20 \mathrm{meV}$ for a decade of excitation, in a similar way as has been observed in compensated GaAs. ${ }^{22}$ This band at $\sim 1.35 \mathrm{eV}$ has been observed in undoped InP grown by MBE and MOCVD under specific conditions of growth, and it has been related to a complex defect incorporating a phosphorus vacancy. ${ }^{19,23}$

We should mention that sample S3 exhibits a weak deep band at $\sim 1.14 \mathrm{eV}$, not shown in the figure, indicating the presence of complex radiative centers. This band has been attributed to emission involving stoichiometry-related defect levels. $^{24,25} \mathrm{PL}$ spectra at $2 \mathrm{~K}$ measured in undoped and Bedoped InP grown at LT by GSMBE, has been found ${ }^{4}$ domi-

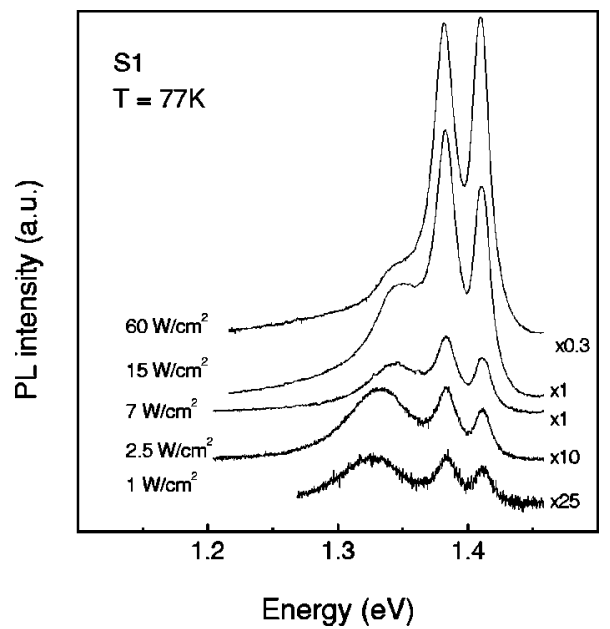

FIG. 5. Dependence of PL spectra with the excitation power density, measured at $77 \mathrm{~K}$, for sample $\mathrm{S} 1\left(p_{300 \mathrm{~K}}=2 \times 10^{17} \mathrm{~cm}^{-3}\right)$.

nated by two broadbands at $\sim 0.8$ and $\sim 1.06 \mathrm{eV}$. The formation of those defect complexes depends strongly on the growth stoichiometry, and therefore on growth conditions such as substrate temperature and phosphorus flux. We have successfully minimized the intensity of these deep bands by a precise control of stoichiometry during ALMBE growth.

\section{CONCLUSIONS}

ALMBE has been shown to be a useful technique for the growth of $p$-type InP at low substrate temperature $\left(\leqslant 400^{\circ} \mathrm{C}\right)$. We have obtained $p$-type Be-doped InP layers of good electrical and optical quality. The room-temperature Hall mobilities are comparable with Be-doped InP layers grown at higher temperatures. PL spectra at $77 \mathrm{~K}$ have a near-band-emission at $\sim 1.41 \mathrm{eV}$ and Be-related emissions at $\sim 1.37 \mathrm{eV}$ (DA) and $\sim 1.38 \mathrm{eV}$ (BA). In addition, we have observed a moving emission band (1.29-1.35 eV) due to a stoichiometry-related defect and a DA pair.

\section{ACKNOWLEDGMENTS}

The authors would like to give special thanks to Dr. P. Huertas for his help in the PL measurements. This work was supported by Project No. TIC95-0563-C05-05 of the Spanish Government.

${ }^{1}$ F. Briones, L. González, and A. Ruiz, Appl. Phys. A: Solids Surf. 49, 729 (1989).

${ }^{2}$ M. L. Dotor, D. Golmayo, and F. Briones, J. Cryst. Growth 127, 619 (1993).

${ }^{3}$ M. L. Dotor, P. Huertas, D. Golmayo, and F. Briones, Appl. Phys. Lett. 62, 891 (1993).

${ }^{4}$ P. W. Yu, B. W. Liang, and C. W. Tu, Appl. Phys. Lett. 61, 2443 (1992).

${ }^{5}$ B. W. Liang, P. Z. Lee, D. W. Shih, and C. W. Tu, Appl. Phys. Lett. 60, 2104 (1992)

${ }^{6}$ B. X. Yang and H. Hasegawa, Proceedings of the Fifth International Conference on InP and Related Materials, Paris, France (IEEE Service Center, Piscataway, 1993).

${ }^{7}$ B. X. Yang and H. Hasegawa, Jpn. J. Appl. Phys., Part 1 33, 742 (1994).

${ }^{8}$ M. L. Dotor, P. Huertas, P. A. Postigo, D. Golmayo, and F. Briones, Electron. Lett. 29, 1270 (1993).

${ }^{9}$ P. A. Postigo, M. L. Dotor, D. Golmayo, and F. Briones, VIII European Workshop on Molecular Beam Epitaxy, Sierra Nevada, Spain, 1995. 
${ }^{10}$ P. A. Postigo, M. L. Dotor, P. Huertas, D. Golmayo, and F. Briones, J. Appl. Phys. 1, 402 (1995).

${ }^{11}$ P. Huertas, M. L. Dotor, P. A. Postigo, D. Golmayo, and F. Briones, Fifth International Conference on Defect Recognition and Image Processing in Semiconductors and Devices, Santander, Spain, September 1993, Inst. of Phys. Conf. Series 135, 1994.

${ }^{12}$ D. Wiley, Semiconductors and Semimetals (Academic, New York, 1975), Vol. 10, p. 91.

${ }^{13}$ E. Kuphal, J. Cryst. Growth 54, 117 (1981).

${ }^{14}$ Y. Kawamura, H. Asahi, and H. Nagai, J. Appl. Phys. 54, 841 (1983).

${ }^{15}$ M. B. Panish, H. Temkim, and S. Sumski, J. Vac. Sci. Technol. B 3, 657 (1985).

${ }^{16}$ V. V. Galvanov, S. G. Metreveli, N. V. Siakaev, and S. P. Starosel'tseva, Sov. Phys. Semicond. 3, 94 (1969).
${ }^{17}$ K. J. Bachmann, E. Buehler, B. I. Miller, J. H. McFee, and F. A. Thiel, J. Cryst. Growth 39, 137 (1977).

${ }^{18}$ T. Uchida, N. Yokouchi, T. Miyamoto, F. Koyama, and K. Iga, J. Cryst. Growth 129, 275 (1993).

${ }^{19}$ A. A. Iliadis and S. Ovadia, J. Appl. Phys. 63, 5460 (1988).

${ }^{20}$ E. Kubota, Y. Ohmori, and K. Sugii, J. Appl. Phys. 55, 3779 (1984).

${ }^{21}$ T. Martin, C. R. Stanley, A. Iliadis, C. R. Whitehouse, and D. E. Sykes, Appl. Phys. Lett. 46, 994 (1985).

${ }^{22}$ P. W. Yu, J. Appl. Phys. 48, 5043 (1977).

${ }^{23}$ B. Wakefield, L. Eaves, K. A. Prior, A. W. Nelson, and G. D. Davies, J. Phys. D 17, L133 (1984).

${ }^{24}$ H. Temkim, B. V. Dutt, W. A. Bonner, and V. G. Keramidas, J. Appl. Phys. 53, 7526 (1982).

${ }^{25}$ P. W. Yu, Solid State Commun. 34, 183 (1980). 